\title{
Mammary analogue secretory carcinoma: A rare salivary gland tumour
}

\author{
B S Jackson, ${ }^{1} \mathrm{MB}$ BCh, MMed (Surg); T L Pratt, ${ }^{1} \mathrm{MB}$ ChB; A van Rooyen, ${ }^{2} \mathrm{MB}$ ChB, MMed (Path) \\ ${ }^{1}$ Department of Surgery, Kalafong Hospital and Faculty of Health Sciences, University of Pretoria, South Africa \\ ${ }^{2}$ National Health Laboratory Services and Department of Anatomical Pathology, Faculty of Health Sciences, University of Pretoria, South Africa
}

Corresponding author: B S Jackson (drbrandonjackson@gmail.com)

\begin{abstract}
Mammary analogue secretory carcinoma (MASC) is a rare and recently described tumour of the salivary glands. MASC has similar histomorphological and immunohistochemical features of secretory carcinoma of the breast. MASC can be mistaken for other salivary gland tumours, especially acinic cell carcinoma. A 28-year-old man was diagnosed with a rare salivary gland tumour in Pretoria, South Africa (SA). To our knowledge, a report of MASC in SA has not previously been published. The surgeons dealing with salivary gland tumours should be aware of the clinical presentation. Current treatment is similar to that of other salivary gland malignancies.
\end{abstract}

S Afr Med J 2017;107(4):304-306. DOI:10.7196/SAMJ.2017.v107i4.12228

Salivary gland malignancy is rare, with a global annual incidence of 3 per 100000 people. $^{[1,2]} \mathrm{A}$ rare salivary gland tumour, mammary analogue secretory carcinoma (MASC), has only recently been described. ${ }^{[3]}$ The few reports and studies concerning MASC have been published in several pathology journals. We report a case of a MASC of the right parotid salivary gland. Ethics approval was obtained from the University of Pretoria Faculty of Health Sciences Research Ethics Committee (ref. no. 384/2016).

\section{Case report}

A 28-year-old man presented to Kalafong Hospital, Pretoria, South Africa, with a 1-year history of a slow-growing right cheek mass. The mass was not painful and there was no history of trauma to the face. Clinically, the patient was well, with a non-tender, firm, mobile $4 \times$ $3 \mathrm{~cm}$ parotid tumour. The right facial nerve was intact. The patient tested negative for HIV. Fine needle aspiration biopsy showed the features to be characteristic of a pleomorphic adenoma. The patient underwent a superficial parotidectomy.

Macroscopically, a tan-white homogeneous nodule of $0.8 \mathrm{~cm}$ was present in the lateral aspect of the parotid gland. Histological examination of sections from the superior aspect showed apparently normal parotid salivary gland tissue. Examination of the lateral aspect showed a relatively circumscribed area with a lobulated architecture traversed by thick fibrous septa (Fig. 1). Microcystic growth with dilated areas and papillary-cystic growth patterns with papillary projections were seen (Fig. 2). Tumour islands punctuated by microcysts were scattered within the sclerosed stroma. The papillae were lined by bland cells with abundant eosinophilic to vacuolated cytoplasm. Some cells had a hobnail appearances and low-grade vesicular round-to-ovoid nuclei, with finely granular chromatin and conspicuous nucleoli (Fig. 3). The wall appeared markedly hyalinised and sclerosed. A chronic lymphocytic inflammatory infiltrate was present in the wall. Partial infiltration into the salivary gland was seen in areas. No necrosis or mitotic figures were present. Inspissated secretions and abundant eosinophilic homogeneous secretory material were present.

Immunohistochemistry showed strong diffuse staining with the keratin marker CK7 and patchy positivity with S-100 protein. DOG-1

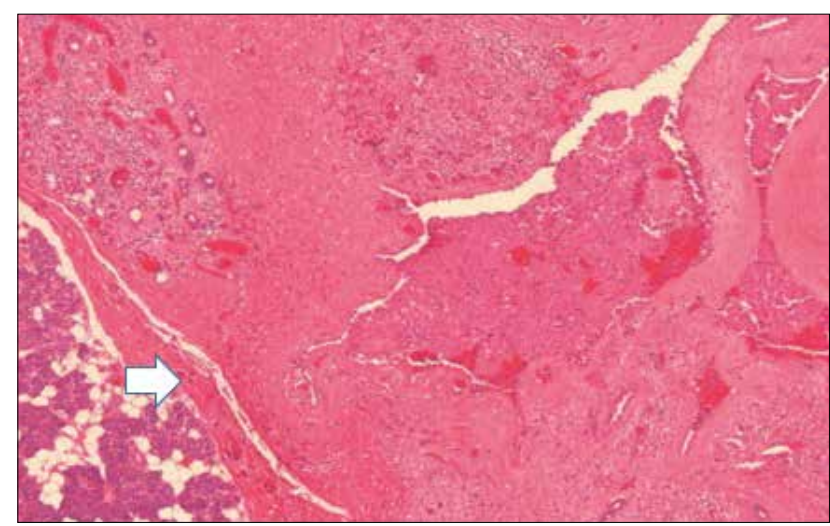

Fig. 1. MASC: multinodular tumour separated by fibrous bands (arrow).

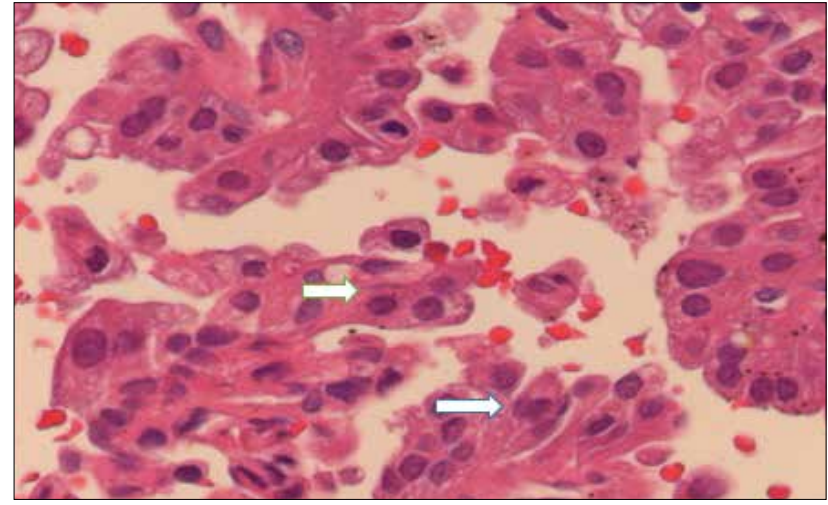

Fig. 2. Area with papillary growth (arrows).

and P63 were negative. Intracytoplasmic and intraluminal mucus was highlighted with periodic acid-Schiff (PAS) (Fig. 4). The histological features were compatible with the rare, recently described MASC. There were no projections of the tumour toward the deep lobe of the parotid gland.

The patient underwent adjuvant radiotherapy. At 8 months post excision, he was well with no signs of recurrence. 


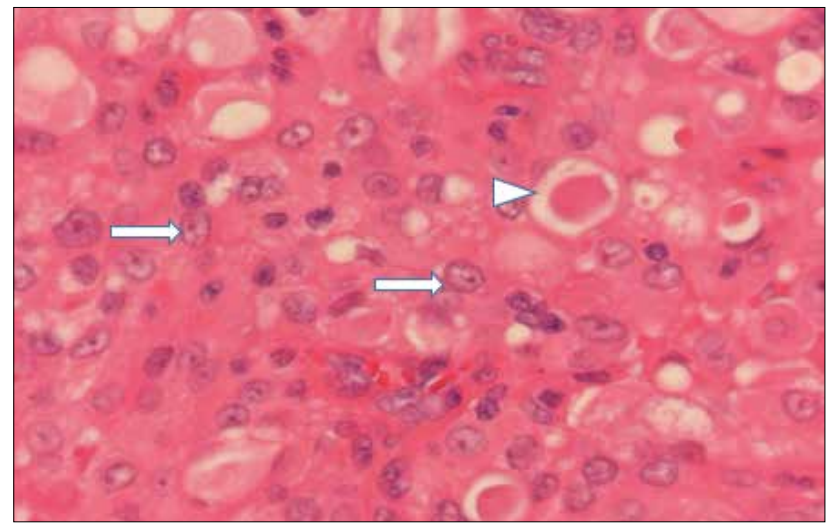

Fig. 3. Area with microcystic pattern and prominent intraluminal secretions (arrow head). Nuclei with finely granular chromatin and conspicuous nucleoli (arrows).

\section{Discussion}

In 2010, Skálová et al. ${ }^{[3]}$ published a description of 16 cases of salivary gland tumours, which were reminiscent of secretory (juvenile) carcinoma of the breast, and subsequently proposed MASC to describe the tumours. ${ }^{[4]}$ Secretory carcinoma is a rare tumour of the breast with a characteristic histological appearance. ${ }^{[5]}$

Breast and salivary gland tissues are derived from the same ectodermal embryonic origin. ${ }^{[2]}$ Salivary and mammary gland tissue have identical ductulo-acinar architecture. Both tumours consist of microcystic and solid areas with abundant vacuolated colloid-like PAS-positive secretions within the microcystic spaces. ${ }^{[6,7]}$ Both tumours are triple (ER/PR/Her-2)-negative. Breast secretory carcinomas are clinically slow growing, recur locally, occur mainly in young females and generally have a favourable outcome. ${ }^{[4]}$ MASC can be clinically slow growing or have an aggressive pattern with metastases and increased mortality. ${ }^{[3]}$

MASC can be mistaken for acinic cell carcinoma; however, MASC does not have acinar cells with cytoplasmic PAS-positive, zymogen-like granules. ${ }^{[3]}$ The majority of MASC cases were previously diagnosed as 'zymogen-poor' acinic cell carcinoma, but also have similar features to low-grade cribiform cystadenocarcinoma, adenocarcinoma not otherwise specified, and low-grade muco-epidermoid carcinoma. ${ }^{[9,10]}$

Acinic cell carcinoma of the breast is composed of cells arranged in microcystic, solid and microglandular areas, and resembles acinic cell carcinoma of the salivary glands. The immunohistochemical and clinicopathological findings of salivary acinic cell carcinoma are similar to those of breast secretory carcinomas. ${ }^{[3]}$

MASC is rubbery and has a white-to-grey surface when cut. Microscopically, the tumour is a circumscribed (but not encapsulated) multinodular mass divided by fibrous septa with microcystic, glandular and solid growth patterns. ${ }^{[4,8]}$ Tumour cells are relatively uniform. ${ }^{[1]}$ The tumour can invade within the salivary gland and can extend into the surrounding structures. ${ }^{[3,8]}$ The tumour cells have low-grade vesicular nuclei, finely granular chromatin and a distinctive centrally located nucleolus. The nucleus is surrounded by pale eosinophilic granular or vacuolated cytoplasm. ${ }^{[3,4]}$ Mitotic rates are usually $0-1$ mitotic figures/10 high-powered fields. ${ }^{[12]}$

Immunohistochemical studies show positive staining with vimentin, mammaglobin, cytokeratin 7 and S-100 protein..$^{[3,8]}$ Mammaglobin and S-100 protein can also be positive in polymorphous lowgrade adenocarcinomas and some adenoid cystic carcinomas. ${ }^{[13]}$ Immunohistochemical stains are negative for DOG-1 and p63. ${ }^{[14]}$

Skálová $e t$ al.$^{[3]}$ showed that MASCs are associated with a recurrent chromosomal translocation $\mathrm{t}(12 ; 15)$ (p13;q25), which results in

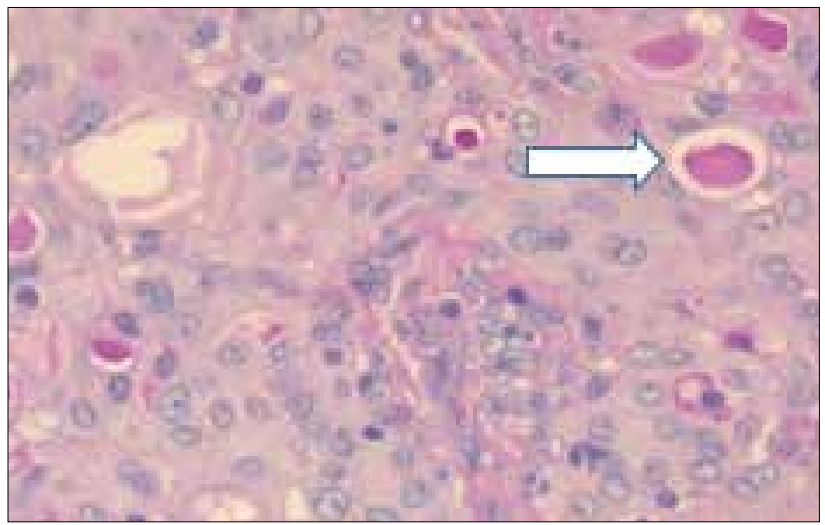

Fig. 4. Secretions are highlighted with PAS stain (arrow).

a fusion gene between the ETV6 gene (chromosome 12) and the NTRK3 gene (chromosome 15). This ETV6-NTRK3 gene encodes for a chimeric tyrosine kinase. ${ }^{[3,4,7,15]}$ Secretory carcinoma of the breast also has a recurrent chromosomal translocation $\mathrm{t}(12 ; 15)$ (p13;q25), which also occurs some cases of myelogenous leukaemia, infantile fibrosarcoma and congenital mesoblastic nephroma. ${ }^{[12]}$ Currently, salivary MASC is the only salivary gland tumour to harbour the recurrent chromosomal translocation $\mathrm{t}(12 ; 15)$ (p13;q25). ${ }^{[4]}$ ETV6-NTRK3 gene fusion definitively diagnoses MASC, but not all laboratories are equipped to perform this highly specialised test.

The reported cases of MASC are diagnosed in the major salivary glands; the majority in the parotid gland. These tumours also occur in the minor salivary glands of the oral cavity. MASC has been documented in the lip, soft palate, hard palate, base of tongue and buccal mucosa. ${ }^{[2,12,16]}$ The reported cases are usually in males, with a male:female ratio of $1.5: 1 \cdot^{[2,4,17]}$ According to a retrospective study from 1990 to 2012 by Min et al.,$^{[8]}$ the average age of diagnosis is 46 years, with a usual range of $14-77$ years. ${ }^{[2,8]}$ The youngest reported case occurred in a 5-year-old girl. ${ }^{[18]}$ The size of MASC ranges from 1.77 to $2.5 \mathrm{~cm} \cdot{ }^{[3,8,10]}$ MASCs in the oral cavity are usually smaller (mean $0.9 \mathrm{~cm}$ ) than those in the major salivary glands. ${ }^{[12,19]}$

MASC is considered to be a low-grade carcinoma that is slowgrowing, painless and with a relatively favourable prognosis. ${ }^{[7,12]}$ It does not usually infiltrate surrounding structures, and perineural and vascular invasion is unusual. ${ }^{[12]}$ MASCs have a $15 \%$ risk of local recurrences, especially if incompletely excised. ${ }^{[7]}$ Simple enucleation of the tumour has a higher risk of local recurrence compared with excision. ${ }^{[7]}$ MASCs have a $20 \%$ risk of lymph node metastases and $5 \%$ risk of distant metastases. Local recurrence usually occurs before distant metastases or tumour-related death. ${ }^{[7]}$

High-grade transformation is associated with an accelerated clinical course and poor outcome. Skálová et al. ${ }^{[3]}$ reported on three patients with high-grade transformed MASC who received parotidectomy. Two of the three received postoperative radiotherapy, the third patient's condition being too poor to complete radiotherapy. All three died of metastatic disease within 2 - 6 years of diagnosis. ${ }^{[7]}$

Clinical stage at diagnosis is the most accurate predictor of prognosis. Treatment recommendations are tentative, as there has been a limited number of cases of MASC with published follow-up data. ${ }^{[20]}$ The role of adjuvant radiotherapy has not been assessed in patients with MASC. However, in the presence of high-grade transformed MASC, radical surgery with neck dissection followed by adjuvant radiotherapy is advised. ${ }^{[7]}$ The optimal follow-up period for MASC is also not currently determined. 
Some ETV6-NTRK3-positive leukaemias respond to tyrosine inhibitors. MASC may therefore also respond favourably by targeting the ETV6-NTRK3 translocation, as a potential therapy, especially for the high-grade transformation MASC. ${ }^{[12]}$

1. Parkin DM, Ferlay J, Curado MP, et al. Fifty years of cancer incidence: CI5 I-IX. Int J Cancer 2010;127(12):2918-2927. https://doi.org/10.1002/ijc.25517

2. Cooper D, Burkey B, Chute D, et al. Mammary analogue secretory carcinoma of the soft palate: A report of two cases. Int J Otolaryngo Head Neck Surg 2013;2(5):174-178. https://doi.org/10.4236/
lof johns.2013.25037

3. Skálová A, Vanecek T, Sima R, et al. Mammary analogue secretory carcinoma of salivary glands containing the ETV6-NTRK3 fusion gene: A hitherto undescribed salivary gland tumor entity? Am J Surg Pathol 2010;34(5):599-608. https://doi.org/10.1097/pas.0b013e3181d9efcc

4. Laco J, Svajdler Jr M, Andrejsc J, et al. Mammary analog secretory carcinoma of salivary glands: A report of 2 cases with expression of basal/myoepithelial markers (calponin, CD10 and p63 protein). Path Res Pract 2013;209(3):167-172. https://doi.org/10.1016/j.prp.2012.12.005

5. McDivitt RW, Stewart FW. Breast carcinoma in children. JAMA 1966;195(5):388-390, https://doi. org/10.1001/jama.195.5.388

6. Petersson F, Lian D, Chau Y, et al. Mammary analogue secretory carcinoma: The first submandibular case reported including findings on fine needle aspiration cytology. Head Neck Pathol 2012;6(1):135139. https://doi.org/10.1007/s12105-011-0283-x

7. Skálová A, Vanecek T, Majewska H, et al. Mammary analogue secretory carcinoma of salivary glands with high-grade transformation. Report of 3 cases with the ETV6-NTRK3 gene fusion and analysis of TP53, B-catenin, EGFR, and CCNDI genes. Am J Surg Pathol 2014;38(1):23-33. https://doi. org $/ 10.1097 /$ pas. 000000000000008

8. Min JJ, Joon SS, Sang YK, et al. Finding and characterizing mammary analogue secretory carcinoma of the salivary gland. Korean J Pathol 2013;47(1):36-43. https://oi.org/10.4132/ koreanjpathol.2013.47.1.36

9. Majewska H, Sang YK, Soon YN, et al. Mammary analogue secretory carcinoma of salivary glands: A new entity associated with ETV6 gene rearrangement. Virchows Arch 2015;466(3):245-254 https:// doi.org/10.1007/s00428-014-1701-8

10. Chiosea SI, Griffith C, Assaad A, et al. Clinicopathological characterization of mammary analogue secretory carcinoma of salivary glands. Histopathol 2012;61(3):387-394. https://doi.org/10.1111/ j.1365-2559.2012.04232.x
11. Inaba T, Fukumura $\mathrm{Y}$, Saito $\mathrm{T}$, et al. Cytological Features of mammary analogue secretory carcinoma of the parotid gland in a 15-year-old girl: A case report with review of the literature. Case Rep Pathol of the parotid gland in a 15-year-old girl: A case report

12. Bishop JA. Unmasking MASC: Bringing to light the unique morphologic, immunohistochemical and genetic features of the newly recognized mammary analogue secretory carcinoma of salivary glands. Head Neck Pathol 2013;7(1):35-39. https://doi.org/10.1007/s12105-013-0429-0

13. Patel KR, Solomon IH, El-Mofty SK, et al. Mammaglobin and S-100 immunoreactivity in salivary gland carcinomas other than mammary analogue secretory carcinoma. Hum Pathol 2013;44(11):2501 2508. https://doi.org/10.1016/j.humpath.2013.06.010

14. Hijazi N, Rahemtulla A, Zhou C, et al. An FNA pitfall: Mammary analogue secretory carcinoma mistaken for acinic cell carcinoma due to cytoplasmic granules. Hum Pathol Case Rep 2014;1(4):5861. https://doi.org/10.1016/j.ehpc.2014.09.008

15. Abe M, Inakia R, Kannoa Y, et al. Molecular analysis of a mammary analogue secretory carcinoma in the upper lip: Novel search for genetic and epigenetic abnormalities in MASC. Int J Surg Case Rep 2015;9:8-11. https://doi.org/10.1016/j.ijscr.2015.02.011

16. Helkama T, Rossib S, Mesimäkia $K$, et al. Mammary analogue secretory carcinoma of minor palat salivary gands: A case report and review of the literture. J Oral Maxillofac Surg Med Patho 2015;27(5):698-702. https:///doi.org/10.1016/j.ajoms.2015.02.005

17. Griffith C, Seethala R, Chiosea SI. Mammary analogue secretory carcinoma: a new twist to the diagnostic dilemma of zymogen granule poor acinic cell carcinoma. Virchows Arch 2011;459(1):117118. https://doi.org/10.1007/s00428-011-1098-6

18. Keisling M, Bianchi M, Pascasio JM. Mammary analogue secretory carcinoma of salivary gland in 5 year old: Case report. Int J Pediatr Otorhinolaryngol 2014;9(4):163-165. https://doi.org/10.1016/j. pedex.2014.09.003

19. Kratochvil FJ III, Stewart JCB, Moore SR. Mammary analogue secretory carcinoma of salivary glands: A report of 2 cases in the lips. Oral Maxillofac Pathol 2012;114(5):630-635. https://doi.org/10.1016/j. oooo. 2012.07 .480

20. Gupta R, Balasubramanian D, Clark JR. Salivary gland lesions: Recent advances and evolving concepts. Oral Maxillofac Pathol 2015;119(6):661-674. https://doi.org/10.1016/j.00oo.2015.02.481

Accepted 8 December 2016 